\title{
Diagnostic Approach in Children with Short Stature
}

\author{
Wilma Oostdijk $^{a} \quad$ Floor K. Grote $^{a}$ Sabine M.P.F. de Muinck Keizer-Schrama ${ }^{b}$ \\ Jan M. Wit ${ }^{\text {a }}$ \\ aDepartment of Pediatrics, Leiden University Medical Center, Leiden, and b Department of Pediatrics, \\ Erasmus MC - Sophia Children's Hospital, Rotterdam, The Netherlands
}

\section{Key Words}

Growth $\cdot$ Short stature $\cdot$ Growth disorders

\begin{abstract}
For early detection of pathological causes of growth failure proper referral criteria are needed, as well as a thorough clinical, radiological and laboratory assessment. In this minireview we first discuss the two consensus-based and one evidence-based guidelines for referral that have been published. The evidence-based guidelines result in a sensitivity of approximately $80 \%$ at a false-positive rate of $2 \%$. Then, relevant clues from the medical history and physical examination are reviewed, and specific investigations based on clinical suspicion listed. In the absence of abnormal clinical findings, an X-ray of the hand/wrist and a laboratory screen are usually performed. Scientific evidence for the various components of laboratory screening is scarce, but accumulated experience and theoretical considerations have led to a list of investigations that may be considered until more evidence is available.

Copyright @ 2009 S. Karger AG, Basel
\end{abstract}

\section{Introduction}

Growth monitoring in infancy and childhood has been part of preventive child health programs for more than a century, and short stature or growth retardation are regarded as relatively early signs of poor health. Growth failure occurs all over the world, and there are no indications that pathological causes of primary or secondary growth failure have a different prevalence in different countries, except for growth failure caused by malnutrition which is obviously strongly dependent on socioeconomic circumstances. Despite the similarity of the clinical presentation of growth failure in different parts of the world, there is a substantial variation in the national guidelines for the diagnostic approach to short stature [1]. Although at a consensus meeting on idiopathic short stature (ISS) [2,3] a list was proposed, there was little scientific basis for it.

In the diagnostic approach two questions are important. (1) Which criteria should be used to refer children with impaired growth and to start diagnostic procedures? (2) What kind of diagnostic approach should be followed in the referred group of children? In this review the literature on this issue will be discussed, and practical guidelines for growth monitoring and diagnostic proce-

\section{KARGER \\ Fax +41613061234 \\ E-Mail karger@karger.ch}

www.karger.com
(C) 2009 S. Karger AG, Basel

0301-0163/09/0724-0206\$26.00/0

Accessible online at:

www.karger.com/hre
Wilma Oostdijk

Department of Pediatrics J6-S, Leiden University Medical Center PO Box 9600

NL-2300 RC Leiden (The Netherlands)

Tel. +31 71526 2824, Fax +31 71524 8198, E-Mail w.oostdijk@lumc.nl 
dures in affluent countries are proposed. The role and methodology of growth monitoring in nonaffluent countries falls outside the scope of this paper.

\section{Referral Criteria for Children with Short Stature}

In the evaluation of growth [supine length or standing height (stature)] there are basically three parameters that can be assessed. First, height can be compared with age references, and expressed as standard deviation score (SDS) or centile position. Height SDS (HSDS) is a measure of the deviation of the individual height from the mean, and is expressed as the number of standard deviations below or above the mean height of the population for the same age and sex. Second, HSDS can be compared with the sex-corrected midparental height (target height) SDS. There are several methods to calculate target height, which we recently summarized [2]. The formula proposed by Hermanussen and Cole [4] may be most firmly based on theoretical arguments, but its value has not been confirmed. If there is a substantial secular trend, the target height formula should be corrected for that (in The Netherlands a correction factor of $4.5 \mathrm{~cm} / 30$ years is used). Third, a longitudinal analysis of growth can be used, either expressed as height velocity ( $\mathrm{cm} /$ year or SDS) in comparison to age references, or as an HSDS deflection (deviation) from the original SDS position (delta HSDS, which is the difference in HSDS between two measurements, preferably approximately 1 year apart).

Guidelines for growth monitoring should ideally have a high sensitivity (true positive rate), so that they detect a high percentage of pathological causes of impaired growth, as well as a high specificity (true negative rate), so that the health system is not overburdened with referrals with a low yield of pathology. As far as we know only four guidelines have been published on referral criteria and diagnostic workup for children with impaired growth. The first was the Finnish guideline, based on a large longitudinal dataset of normal infants and children [5-7]. This guideline is still in use in Finland, and is based on cutoff limits for HSDS minus target height SDS $( \pm 2.3)$ and on a range of cutoff limits for delta HSDS (depending on age and the length of the age interval). There are no data on its sensitivity and specificity.

Two growth monitoring guidelines were based on consensus meetings $[8,9]$. The United Kingdom guideline ('Coventry Consensus') concentrates on the referral of children with short stature after a single height measurement at school entrance [a height $<0.4$ th centile $(-2.66$
SDS) at 5 years of age] [8]. Recently a discussion about this criterion was started after the publication of a systematic review by Fayter et al. [10] about height screening during the primary school years. In an editorial, Fry [11] pleaded for measuring parents and at least three or four height measurements to be put back on the UK agenda. Hall et al. [12] agreed that the issue of adjusting the school entry height measurement for parental height deserved to be revisited, but also mentioned the low coverage and inaccurate measurements in the UK and pleaded for a better implementation of the 'Coventry Consensus'.

The Dutch consensus guideline focused on the three auxological referral criteria mentioned above: HSDS, change in HSDS (HSDS deflection) and distance between HSDS and target height SDS [9]. Besides these three growth criteria, it was emphasized that it specifically assesses the presence of body disproportion, defined as an abnormal sitting height/height ratio, in view of the high likelihood of a primary growth disorder in short children with abnormal body proportions. Other criteria included the presence or absence of dysmorphic features, specific symptoms (such as those associated with emotional deprivation), or a history of low birth weight and/or length (small for gestational age). The sensitivity of this guideline was reasonable [13], but it was shown that application of these auxological criteria would lead to far too many unnecessary referrals (approximately 25\%), and thus to an unacceptably low specificity of 75\% [14].

For this reason an evidence-based guideline for the referral of children with short stature was developed (fig. 1) [15]. A large difference in the efficacy and efficiency of referral criteria between infants and toddlers (0- to 3 -year-olds) and children between 3 and 10 years old was found. Between 0 and 3 years of age the decision rules involving target height and length deflection had a low predictive value, and the only useful referral rule for this age group was based on an extremely low or repeatedly low HSDS. With such criteria, only $15-26 \%$ of the growth disorders studied was detected, at a specificity of approximately $98 \%$. In subsequent studies comparing growth of 0 - to 3 -year-old children with celiac disease (CD) or cystic fibrosis (CF) we showed that body mass index is a better auxological tool than length [16-18].

In our analysis the best decision rule for detecting children of 3-10 years with pathology was the 'short for target height' rule (HSDS minus target height SDS $<2$ and HSDS <2), detecting $77 \%$ of the girls with Turner syndrome and $59 \%$ of the children with short stature due to mixed pathology as detected after referral. The combination of the HSDS rule (an HSDS <-2.5), the target 


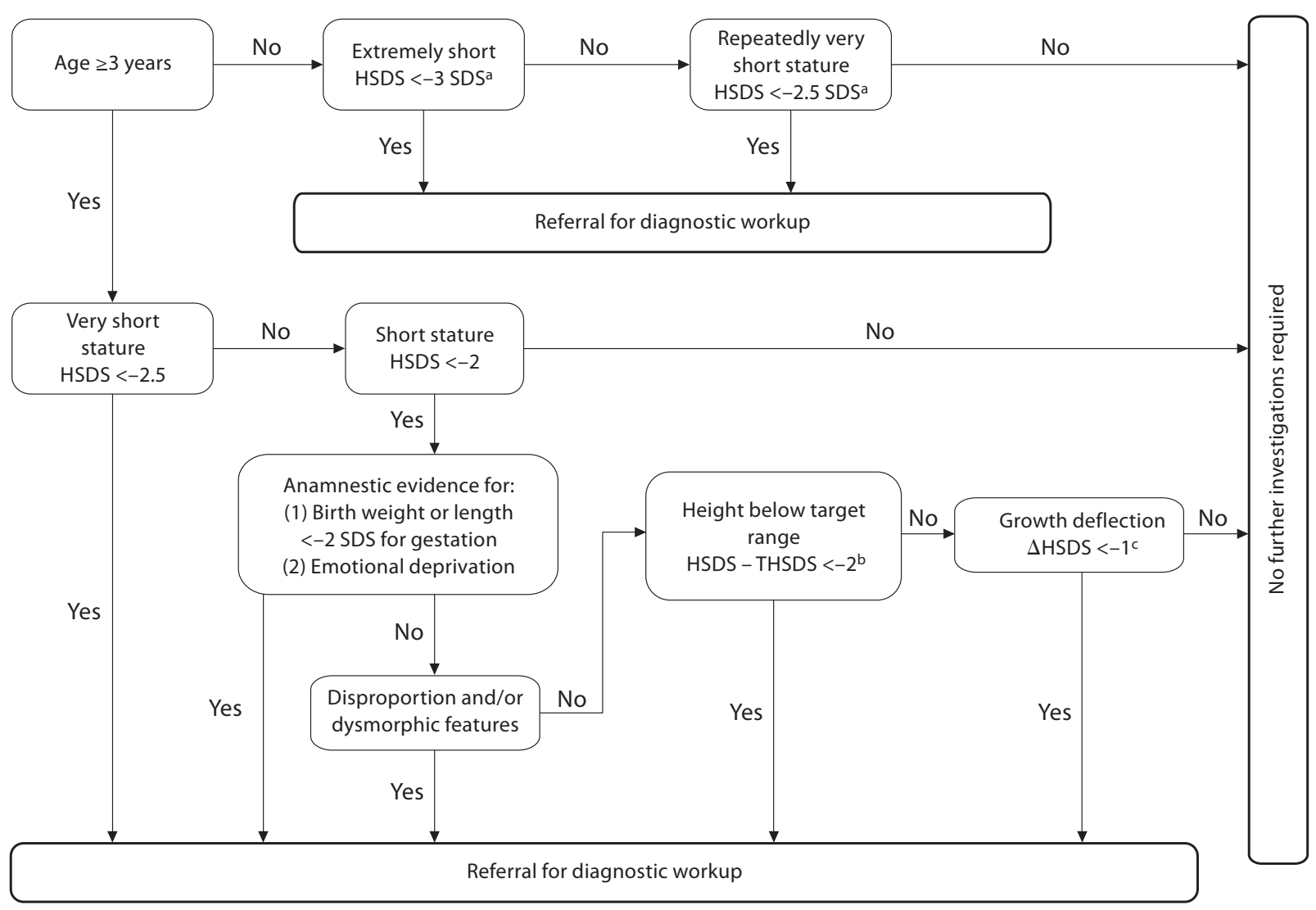

Fig. 1. Evidenced-based guideline for referral of children with short stature and age $0-10$ years. ${ }^{a}$ These referral criteria only apply to children with a birth weight $\geq 2,500 \mathrm{~g}$. ${ }^{\mathrm{b}}$ Children with a growth disorder and tall parents can be missed if a child is $\geq 3$ years old and height is $>2.5 \mathrm{SD}$ below target height. In spite of

height rule and the height deflection rule (an HSDS decrease $>1.0$ SD) detected $86 \%$ of girls with the Turner syndrome and $77 \%$ of children who were short because of various disorders. The estimated specificity of this approach was $98 \%$. Insufficient data were available to give evidence-based guidelines for children $>10$ years. One might consider referral and diagnostic procedures in this age group if HSDS $<-2.5$.

If one compares the UK consensus guideline and the recent evidence-based Dutch guideline, it is clear that the sensitivity of the latter must be higher, and that pathology will be detected at a younger age. For example, based upon the Dutch evidence-based guidelines a diagnosis would be made before the age of 3 years in $30 \%$ of the children with pathology. In contrast, according to the UK
HSDS, referral and further investigations should be considered. ${ }^{c}$ These guidelines are proposed for screening purposes only. In individual cases, especially when growth deflection occurred recently: in spite of HSDS, referral and further investigations should be considered. HSDS = Height SDS; THSDS = target height SDS .

consensus these children would not have been diagnosed at that point, as this consensus recommends a single measurement at the age of 5 years [13]. On the other hand, the specificity of the UK guideline is considerably higher (99.5 vs. $98 \%)$. Validation of these and other guidelines in prospective studies are needed, possibly in combination with a cost-benefit analysis, before a definite conclusion can be drawn.

\section{Diagnostic Procedures}

\section{Classification of Growth Disorders}

When a child is referred to a pediatrician, the diagnostic process is aimed at detecting the cause of his/her 
shortness. In most diagnostic classifications, including the ESPE Classification of Paediatric Endocrine Diagnoses, three main groups of growth disorders are distinguished: primary growth disorders (conditions thought to be intrinsic to the growth plate), secondary growth disorders (conditions that change the milieu of the growth plates), and a remaining group in which no recognizable cause is found (table 1) [19]. This last group is currently known as ISS. In two recent reviews $[2,20]$ and a consensus statement, diagnosis and management of ISS were extensively described [3]. ISS is subdivided into familial and nonfamilial short stature, and both can be further subcategorized into children with delayed and normal puberty. The last category is roughly equivalent with the clinical entity 'constitutional delay of growth and puberty'. For a good differential diagnosis the patient's history, physical examination and growth data should be collected to determine signs and symptoms that may indicate a specific disease. The diagnostic approach to the short infant or child can be divided into three consecutive steps.

\section{First Step}

The first step consists of a thorough medical and family history and physical examination. Relevant points in the history include birth characteristics, symptoms suggestive of chronic organic diseases, psychiatric diseases and/or severe emotional disturbances (table 2) [2, 21, 22]. The physical examination should aim at detecting clues for one of the many causes of short stature. First, supine length or height, weight, head circumference, sitting height (or lower body segment) and arm span will be measured. One should also consider measuring forearm length, as a short forearm is an important marker of SHOX haploinsufficiency [23]. Measurements will be compared with the best available references. For height, weight and head circumference the most recent available growth references for the country or specific ethnic population should be used. References for sitting height/height and arm span are scarce and a choice for the most appropriate reference has to be made [24-29]. Abnormal body proportions are strongly suggestive of a form of skeletal dysplasia. A careful examination for facial and body dysmorphic features should also be performed to detect syndromes (table 3).

\section{Second Step}

The second step consists of specific investigations, depending on specific clinical clues at the medical history and physical examination, for example the presence of disproportions or dysmorphic features. An international inventory revealed that in only $45 \%$ of the responding countries specific guidelines on diagnostic procedures in children with short stature in secondary health care were reported, but most of the mentioned protocols were not nationally implemented [1]. In the literature some protocols have been described summing up the various investigations to consider, but flow diagrams of how to choose a specific investigation are scarce [30-32]. We propose the diagram shown in figure 2 as the second step in the diagnostic approach.

When skeletal dysplasia is suspected based upon disproportions, radiographic analysis is important to get a more precise diagnosis or to narrow down the number of possibilities. Various guidelines for radiographic analysis of disproportionate short stature are available. They had recently been summarized by Kant et al. [33] and based upon this review a recommendation for radiographic analysis was made (table 4). Results of this radiographic analysis can guide targeted molecular DNA analysis and can contribute to an efficient approach to diagnosing growth disorders.

There are many syndromes associated with short stature. When dysmorphic features in a child with short stature are present, diagnostic investigations have to focus on syndromes. If there are signs of Turner syndrome, obviously a karyotype has to be made, and even in the absence of such features it is generally advised to order a karyotype in a short girl. It has also been proposed to perform a karyotype in a short boy with unexplained short stature [34], but in view of the high costs this may be restricted to boys with some sign of genital abnormality [3].

In the last decades more and more genetic causes of syndromes have been unraveled. If such a syndrome is suspected, the pediatrician, in collaboration with the clinical geneticist, may consider targeted DNA analysis. For a systematic diagnostic approach we refer to a review by Kant et al. [33], in which an overview of the different genetic causes of short stature is given, and a flow chart for molecular analyses is proposed. For a recent review on the diagnostic procedures to detect genetic disorders in the growth hormone-insulin-like growth factor I axis we refer to the paper by Walenkamp and Wit [35].

\section{Third Step}

As in the majority of cases no specific clues from medical history and physical examination will be present, the third step is a nonspecific radiographic and laboratory screening.

There is wide consensus that as part of the diagnostic workup of the short child a radiograph of the hand and 
Table 1. Causes of short stature according to the ESPE classification

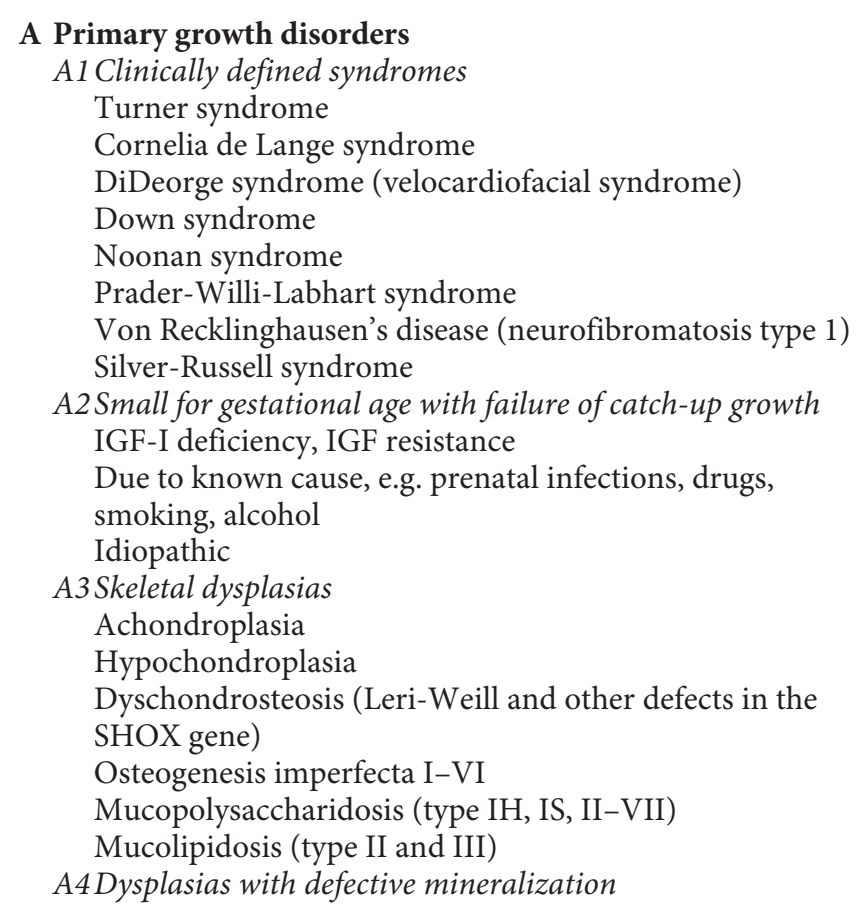

\section{B Secondary growth disorders}

B1 Insufficient nutrient intake (malnutrition)

B2 Disorders in organ systems

Cardiac disorders

Pulmonary disorders, e.g. cystic fibrosis

Liver disorders

Intestinal disorders, e.g. Crohn's disease, malabsorption syndromes

Short bowel syndrome

Renal disorders, e.g. Fanconi syndrome, renal acidosis

Chronic anemia

B3 Growth hormone deficiency (secondary IGF-I deficiency) Idiopathic

Genetic (HESX1, PROP1, POU1F1, LHX3, LHX4,

GHRHR, GH)

Associated with syndromes or cerebral or facial malformations, e.g. septo-optic dysplasia, empty sella syndrome

Associated with prenatal infections, e.g. rubella

Acquired (craniopharyngioma, other pituitary tumors, e.g. germinoma, hamartoma)

Head trauma

Central nervous system infections

Granulomatous diseases, e.g. histiocytosis
B4 Other disorders of the growth hormone-IGF axis (primary IGF-I deficiency and resistance)

Bioinactive growth hormone

Abnormalities of the growth hormone receptor (growth hormone insensitivity syndrome, Laron syndrome)

Abnormalities of $\mathrm{GH}$ signal transduction, e.g. STAT5B

defect

ALS (acid-labile subunit) deficiency

IGF-I deficiency

IGF resistance (IGF1R defects, postreceptor defects)

B5 Other endocrine disorders

Cushing syndrome

Hypothyroidism

Leprechaunism

Diabetes mellitus (poorly controlled)

Short adult stature caused by accelerated bone maturation, e.g. precocious puberty, hyperthyroidism, congenital adrenal hyperplasia, exogenous estrogens or androgens

B6 Metabolic disorders

Disorders of calcium and phosphorus metabolism

Disorders of carbohydrate metabolism

Disorders of lipid metabolism

Disorders of protein metabolism

B7 Psychosocial

Emotional deprivation

Anorexia nervosa

Depression

B8 Iatrogenic

Systemic glucocorticoid therapy

Local glucocorticoid therapy (inhalation, intestinal, other)

Other medication

Treatment of childhood malignancy

Total body irradiation

Chemotherapy

Other specified iatrogenic causes

\section{Idiopathic short stature}

C1 Familial (idiopathic) short stature

C2 Non-familial (idiopathic) short stature

Classification according to the ESPE classification [19]. 
Table 2. Special points of interest in medical history and physical examination of short children

Issue $\quad$ Interpretation

\section{Medical history}

Birth length, weight, head circumference, gestational age

Special features regarding pregnancy (intrauterine growth retardation, drug intoxications, infections) and birth (breech delivery, asphyxia, jaundice)

Previous growth data

Age at start of pubertal signs (girls: breast development, boys pubic hair and testicular enlargement)

Previous diseases and operations, medication (e.g. inhalation therapy with corticosteroids)

Medical history of the various systems, e.g. symptoms suggestive of heart, pulmonary, intestinal (abdominal pain, distended abdomen, diarrhea, constipation), kidney, endocrine (fatigue) and CNS (headache, visual disturbance nausea, vomiting); fatigue

Hypotonia, snoring

Feeding history first year/nutrition (if nutrition is poor, weight is usually affected more than height)
Compare with intrauterine growth standards (SGA or AGA?; proportionate or disproportionate?)

Fetal (intrauterine) growth retardation can lead to an SGA birth weight, and $15 \%$ of SGA born children do not catch up in height. Intrauterine intoxications and infections can lead to diminished fetal growth. Pituitary dysfunction is associated with breech delivery and prolonged jaundice

A complete growth curve is essential for a good assessment of a growth disorder

Early, normal or delayed pubertal onset

Organic or iatrogenic causes

Organic causes (e.g. celiac disease). CNS symptoms suggestive of brain tumor. Fatigue can be a symptom of anemia, celiac disease, IBD, renal disorder, hypocortisolism
Country of origin, ethnicity

Consanguinity

Parental height (preferably measured, rather than reported)

Global impression of the parents

Tempo of puberty of the mother (age at menarche)

Tempo of puberty of the father (age at start of pubic hair, age at growth spurt, prolonged growth)

Family history (autoimmune diseases, thyroid disorders, growth disorders, skeletal disorders, endocrine disorders)

Milestones delayed, intellectual retardation

Social environment and psychosocial functioning; school performance (grade, social behavior, physical activities); social contacts; personality development (self-reliance); vitality (mood, activities, sleeping, drinking); behavior (mascot, clown, aggressive); unexplained physical complaints; parental attitude
Prader-Willi syndrome

In SGA and Prader-Willi syndrome feeding difficulties in first year frequently occur.

In case of failure to thrive detailed assessment of feeding pattern. In toddlers: note symptoms of emotional deprivation. In adolescents: note symptoms of anorexia nervosa

This influences the decision about which reference charts will be used Strongly increases the likelihood of recessive genetic disorders

Required for calculating target height

Dysmorphic features (specially facial and hands), body proportions

To assess likelihood of a familial pattern of delayed puberty

To assess likelihood of a familial pattern of delayed puberty

To assess likelihood of a genetic cause

Associated with syndromes, chromosomal disorders, metabolic disorders

Neglect, emotional deprivation, undernutrition, depression, anorexia nervosa. Impression of parental concern and support 
Table 2 (continued)

Issue

\section{Physical examination}

Length or height, weight, head circumference, sitting height (or lower body segment), span, forearm length, weight, weight-for-height, BMI, head circumference are compared with reference charts

Underweight

Overweight, obese (note: children with nutritional obesity are often relatively tall for chronological age)

Dysmorphic features

Frontal bossing, mid-facial hypoplasia

Moon face, facial plethora

Inspection of tonsils

Thyroid size

Slow pulse rate, slow relaxation of the Achilles tendon reflex

\begin{tabular}{ll}
\hline Hypertension & Kidney disease, Cushing's syndrome \\
\hline Lobulated abdominal fat & GH deficiency \\
\hline Abdominal distension & Celiac disease \\
\hline Hepatomegaly, splenomegaly & Hepatic or metabolic disorder \\
\hline Pubertal stage & Early, normal or late puberty \\
\hline Micropenis & Hypogonadism, hypopituitarism \\
\hline Cryptorchidism & Hypogonadism \\
\hline Virilization & Cushing's syndrome \\
\hline Muscular hypotonia & Muscular disorder \\
\hline Fundoscopy, vision, visual field defect & CNS pathology \\
\hline Signs of neglect or abuse & Emotional deprivation \\
\hline \multicolumn{1}{c}{ SGA = Small for gestational age; AGA = appropriate for gestational age. } \\
\hline
\end{tabular}

A high sitting height/height ratio (or low upper/lower segment ratio) is suggestive of skeletal dysplasia. A low span and short forearm are suggestive of SHOX defect

Intestinal disorders, hypocortisolism, metabolic disorders, SGA

Hypothyroidism, Cushing's syndrome, GH deficiency, pseudohypoparathyroidism

Primary growth disorders (syndromes)

GH deficiency or resistance, IGF-I deficiency

Cushing's syndrome

Watch for tonsillar hypertrophy

Enlarged (or decreased) in Hashimoto thyroiditis

Hypothyroidism

Kidney disease, Cushing's syndrome

Hepatic or metabolic disorder

Hypogonadism, hypopituitarism

ypogonadism

wrist is useful [1]. On this X-ray, bone age is determined, which can also be used for adult height prediction with one of the available atlases $[36,37]$. The degree of bone age delay is an aid in distinguishing between various classes of growth disorders. In addition, on a hand/wrist X-ray, abnormalities associated with SHOX haploinsufficiency can be seen, as well as signs of vitamin D deficiency [23].

If there are no signs of any dysmorphic features or disproportion, nor of any chronic disease, most centers perform a screening set of laboratory investigations. How- ever, there is no consensus about which tests should be performed $[1,2]$, and scientific evidence supporting the various proposed lists is scarce. Ideally, the choice of the laboratory parameters should depend on the prevalence of the disease, the frequency with which the disease presents with only growth retardation, the sensitivity and specificity of the test, and the implications for the patient.

We have collected evidence that only for one test the evidence should be considered sufficient. In a systematic review we found a strong scientific basis to check for CD 
Table 3. Dysmorphic features in short stature and associated syndrome

\begin{tabular}{|c|c|}
\hline Dysmorphic feature & Associated syndrome \\
\hline $\begin{array}{l}\text { Short nose with anteverted } \\
\text { nostrils }\end{array}$ & Smith-Lemli-Opitz \\
\hline Continuous eyebrows & Cornelia de Lange \\
\hline Absence of adipose tissue & Leprechaunism \\
\hline Alopecia & Progeria \\
\hline Ambiguous genitalia/ & Mixed gonadal dysgenesis/ \\
\hline abnormal genitalia & $\begin{array}{l}46, \mathrm{XY} / 45 \mathrm{X} \text { chromosomal } \\
\text { mosaicism/Smith-Lemli-Opitz/ } \\
\text { Aarskog }\end{array}$ \\
\hline $\begin{array}{l}\text { Asymmetry of the face/ } \\
\text { arms/legs }\end{array}$ & Russell-Silver \\
\hline Bicuspid aortic valve & Turner \\
\hline Bird-headed face & Seckel \\
\hline Broad thumbs and toes & Rubinstein-Taybi \\
\hline Cataract (congenital) & Hallermann-Streiff \\
\hline Cleft lip and/or palate & Growth hormone deficiency \\
\hline Clinodactyly & Russell-Silver \\
\hline Coarctatio aortae & Turner \\
\hline Cryptorchism & $\begin{array}{l}\text { Noonan, Prader-Willi, } \\
\text { Rubinstein-Taybi }\end{array}$ \\
\hline Cubiti valgi & Turner \\
\hline Digital V missing/no nails & Coffin-Siris \\
\hline Disproportion & Skeletal dysplasias \\
\hline Elfin face & Williams \\
\hline Epicanthus & Down \\
\hline High arched palate & $\begin{array}{l}\text { 22q11 deletion syndrome, } \\
\text { SHOX }\end{array}$ \\
\hline Hirsutism & Coffin-Siris, Cornelia de Lange \\
\hline Hypogonadism & Robinow, Smith-Lemli-Opitz \\
\hline Hypoplastic nipples & Turner \\
\hline Hypospadia & $\begin{array}{l}46, \mathrm{XY} / 45 \mathrm{X} \text { chromosomal } \\
\text { mosaicism }\end{array}$ \\
\hline Inverted nipples & Turner \\
\hline Lymphedema (congenital) & Turner \\
\hline Madelung deformity & Leri-Weill, SHOX abnormalities \\
\hline Micropenis & $\begin{array}{l}\text { Prader-Willi, growth hormone } \\
\text { deficiency }\end{array}$ \\
\hline Muscular hypotonia & Down, Prader-Willi \\
\hline Nail convexity/dysplasia & Turner \\
\hline Nevi (multiple) & Turner \\
\hline Ptosis & $\begin{array}{l}\text { Aarskog, Dubowitz, Noonan, } \\
\text { Turner }\end{array}$ \\
\hline Pulmonary valvular stenosis & Noonan \\
\hline Shawl scrotum & Aarskog \\
\hline $\begin{array}{l}\text { Short } 4 \text { th and } 5 \text { th meta- } \\
\text { carpals }\end{array}$ & Pseudohypoparathyroidism \\
\hline Single central incisor & Growth hormone deficiency \\
\hline Small hands/feet & Prader-Willi \\
\hline Telangiectasia in face & Bloom \\
\hline Triangular face & Russell-Silver \\
\hline Webbed neck & Noonan, Turner \\
\hline
\end{tabular}

in short children [38]. We showed that in $2-8 \%$ of the children with short stature and no gastrointestinal symptoms $\mathrm{CD}$ may be the underlying cause, and the risk increases to $19-59 \%$ if other causes for short stature are excluded. For a proper interpretation of the results of these tests total IgA remains important, as $7-10 \%$ of the $\mathrm{CD}$ patients have IgA deficiency [39]. Although anti-tissue transglutamase and anti-endomysium antibodies have a high sensitivity and specificity, the gold standard for the definite diagnosis of $\mathrm{CD}$ remains an intestinal biopsy.

In most centers hematological parameters, such as cell indices, leukocyte differentiation, and erythrocyte sedimentation rate, are included in the laboratory screening, to detect or exclude anemia and infections or inflammatory diseases. Our international inquiry showed that these tests were recommended in most countries with guidelines for diagnostic workup [1]. We did not perform a thorough literature search on the prevalence of short stature in combination with anemia, but the available literature shows that there is a strong relationship between thalassemia, sickle cell disease and growth retardation [40-43]. Likewise, Stephensen [44] showed evidence of the association between infectious diseases in general and linear growth. Anemia and inflammation parameters can also be the first signs of other growth-related disorders like inflammatory bowel diseases, CD or CF. The erythrocyte sedimentation rate is also an important parameter in detecting inflammatory bowel diseases. We have shown that the prior probability of CF in infants or children with a low weight or length for age is too low for a reliable result of a sweat test [16]. The same conclusion might be drawn for the infectious parameters, but experimental data are lacking. However, as anemia and infectious parameters are important for the detection of other growth-related disorders, and as they are noninvasive for the patient and relatively cheap, we recommend these parameters to be kept in the routine diagnostic workup of short children.

Another possible category of the routine diagnostic workup contains parameters to exclude liver diseases. Especially ASAT and ALAT were recommended in more than $50 \%$ of the countries with an existing guideline for the assessment of short stature [1], but $\gamma \mathrm{GT}$ was usually considered optional. Although Sokol and Stall [45] concluded that growth retardation is common in children with chronic liver disease, in more than 30 years of experience we have not encountered any asymptomatic short child in whom liver function tests revealed a liver disorder. Therefore, we believe that it is extremely unlikely that the sole presenting sign of a liver disorder is growth retardation. However, we have not been able to perform an 


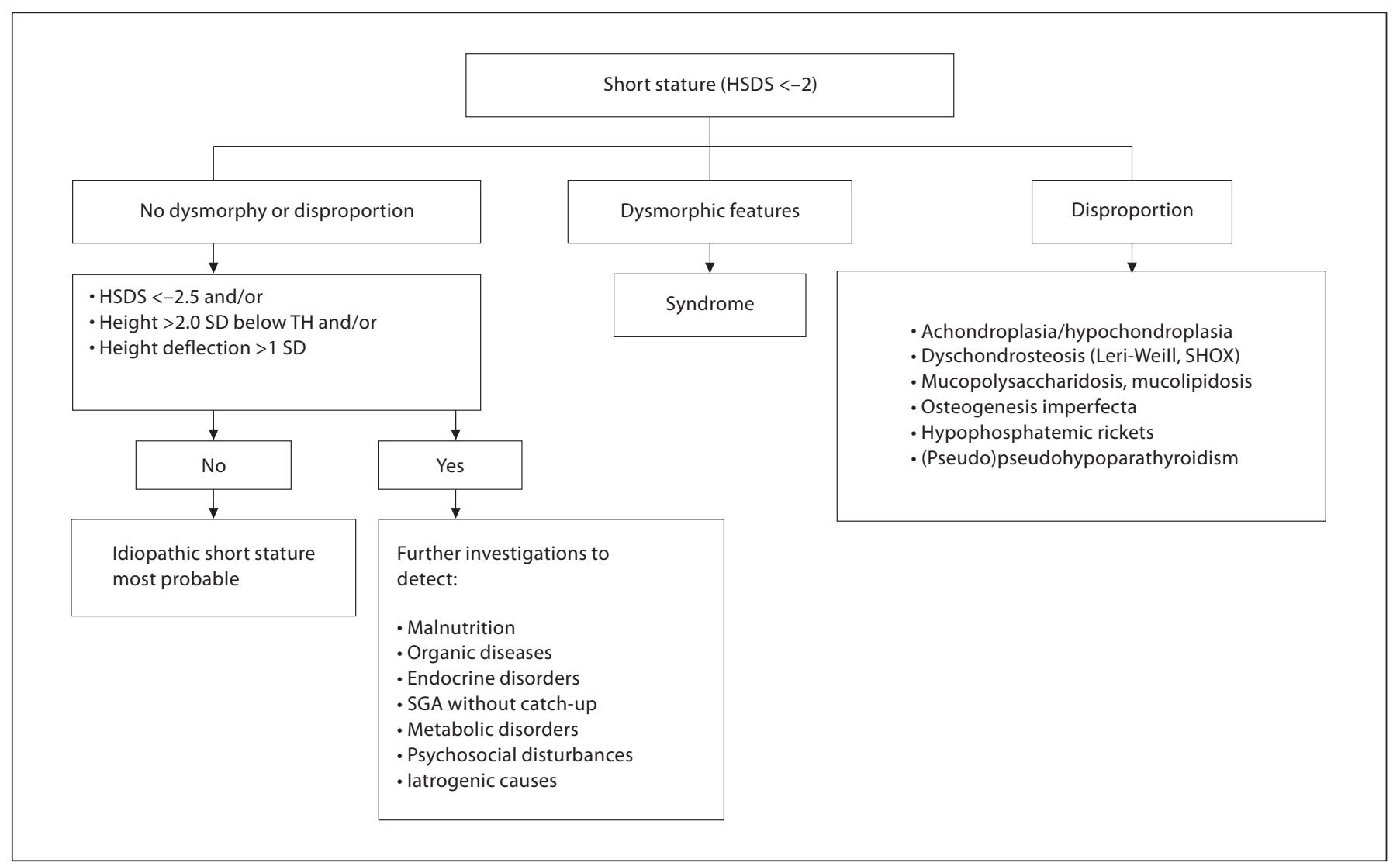

Fig. 2. Diagnostic approach in children with short stature. $\mathrm{TH}=$ Target height; $\mathrm{SGA}=$ small for gestational age .

extensive literature search on the prevalence of monosymptomatic short stature at diagnosis in children with liver disorders and further research has to be performed to collect experimental evidence on the issue. At present, we consider it justified to remove these parameters from the routine diagnostic workup of short stature.

The next category of serum determinations, in combination with routine screening of a urine sample, is aimed at detecting renal diseases, calcium/phosphate disorders and malabsorption. More than $50 \%$ of the countries with guidelines for a diagnostic workup in children with short stature recommended that electrolytes, albumin and creatinine should be evaluated [1]. This agrees with the literature that shows that several renal diseases are in fact associated with short stature and that growth retardation is often present at diagnosis while other clinical symptoms are still absent [46-49]. An acid-base equilibrium measurement, an easy and cheap test to screen for kidney diseases such as renal acidosis, was only recommended in $32 \%$ of the countries with guidelines [1] and was seldom done in the hospi- tals familiar with the Dutch Consensus Guideline [50]. Probably the main reason for skipping this test was that an extracapillary blood sample is necessary, besides the routine venous blood sample to rule out other diseases. Preliminary results of a study on the growth of infants and children with renal tubular acidosis have confirmed previously published data that several patients with distal renal tubular acidosis often show failure to thrive as the first and main symptom [51-55]. However, this diagnosis is rare, and virtually always made in the first 3 years of life. We, therefore, propose to limit this investigation into growth failure in that age group.

There seems to be international consensus on testing $\mathrm{TSH}$ and free $\mathrm{T}_{4}$ to diagnose or rule out hypothyroidism in the diagnostic workup in children with short stature [1]. Although a systematic literature search has not been performed, clinical experience combined with the prevalence of hypothyroidism is in favor of including these tests in the diagnostic workup [56]. 
Table 4. Recommendations for radiographic analysis in children with disproportionate growth disorders [from 33]

\begin{tabular}{ll}
\hline Part of the skeleton & Points of interest \\
\hline Skull (PA and lateral) & $\begin{array}{l}\text { Shape, craniosynostosis, size of } \\
\text { fontanels }\end{array}$ \\
\hline $\begin{array}{l}\text { Spine and ribs } \\
\text { (AP and lateral) }\end{array}$ & $\begin{array}{l}\text { Shape of spine } \\
\text { (scoliosis, kyphosis, lordosis) } \\
\text { Width of the spinal canal: caudal } \\
\text { narrowing of the interpeduncular } \\
\text { distance or stenosis lumbar spinal } \\
\text { canal? }\end{array}$ \\
$\begin{array}{l}\text { Shape and size of all vertebrae } \\
\text { (flattening?) }\end{array}$ \\
\hline $\begin{array}{l}\text { Abnormalities of the ribs, scapula or } \\
\text { clavicula }\end{array}$ \\
\hline $\begin{array}{l}\text { Size and shape of the iliac wings and } \\
\text { ossification pattern }\end{array}$ \\
\hline Long bones: 1 arm and \\
$\begin{array}{l}\text { Measurements of the bone length for } \\
\text { differentiation between rhizomelic } \\
\text { and acromelic shortening }\end{array}$ \\
\hline Left hand (PA) & $\begin{array}{l}\text { Bone age, shortening of the } \\
\text { metacarpals, oligodactyly, } \\
\text { polydactyly, syndactyly, Madelung } \\
\text { deformity }\end{array}$ \\
\hline
\end{tabular}

$\mathrm{PA}=$ Posteroanterior view; $\mathrm{AP}=$ anteroposterior view.

As growth hormone deficiency is one of the most important conditions to be detected by auxological screening and because of its relatively high prevalence (reported prevalence $1: 2,500$ to $1: 6,000$ ) it is obvious that IGF-I should be kept in the diagnostic workup $[57,58]$. This opinion is shared by most of the countries with current guidelines [1]. IGFBP-3 adds little to the evaluation of children with short stature, except in children younger than 3 years, where low IGFBP-3 levels are helpful in the diagnosis of growth hormone deficiency [59].

FSH is recommended as a screening tool for Turner syndrome in the diagnostic workup for short stature in $50 \%$ of the countries with guidelines [1]. In our retrospective study, FSH was determined in less than a quarter of the girls in the group of children correctly referred to secondary health care [13]. When the age rules recommended by pediatric endocrinologists (to measure plasma FSH only in girls $<2$ years and $>9$ years) were applied, the figures hardly changed. From the literature, as well as from clinical experience, it is known that the diagnosis of Turner syndrome should be considered in any girl with
Table 5. Proposed laboratory screening in short children

\begin{tabular}{|c|c|}
\hline Laboratory determinations & To detect or exclude \\
\hline \multicolumn{2}{|l|}{ Blood } \\
\hline $\begin{array}{l}\mathrm{Hb}, \mathrm{Ht} \text {, leukocytes, red cell indices, } \\
\text { leukocyte differentiation, ESR }\end{array}$ & Anemia, infections \\
\hline $\begin{array}{l}\text { Creatinine, sodium, potassium, } \\
\text { calcium, phosphate, alkaline } \\
\text { phosphatase, iron, ferritin, albumin }\end{array}$ & $\begin{array}{l}\text { Renal disorders, calcium/ } \\
\text { phosphate disorders, } \\
\text { malabsorption }\end{array}$ \\
\hline Acid-base balance $(0-3 \text { years })^{\mathrm{a}}$ & Renal tubular acidosis \\
\hline $\begin{array}{l}\text { IgA-anti-endomysium antibodies }{ }^{\mathrm{b}} \text {, } \\
\text { IgA-anti-tissue transglutaminase } \\
\text { antibodies }^{\mathrm{b}} \text {, total IgA }\end{array}$ & Celiac disease \\
\hline $\mathrm{TSH}$, free $\mathrm{T}_{4}$ & Hypothyroidism \\
\hline IGF-I & $\begin{array}{l}\text { Growth hormone } \\
\text { deficiency }\end{array}$ \\
\hline
\end{tabular}

Urine

Glucose, protein, blood, sediment Kidney disorders

If the above tests are negative

Blood

Chromosome analysis

Turner syndrome

a In children older than 3 years with asymptomatic growth failure renal tubular acidosis is very unlikely.

${ }^{b}$ If at least one of these parameters is positive, an intestinal biopsy is needed to confirm the diagnosis of celiac disease.

${ }^{c}$ If no etiology of short stature is found in girls, a karyotype has to be done.

unexplained short stature $[60,61]$. Therefore, we believe that irrespective of the FSH result, a chromosomal analysis should be carried out in each girl in whom the initial laboratory screening has not shown an abnormality. Thus, we did not include FSH in the recommended list of laboratory investigations.

There are some reports suggesting that zinc ( $\mathrm{Zn})$ deficiency may be a cause of short stature, and that the determination of $\mathrm{Zn}$ might be considered as part of the laboratory screening. Reasons to consider $\mathrm{Zn}$ deficiency as cause of short stature are that $\mathrm{Zn}$ is essential for somatic growth in children and that even in developed countries marginal to moderate $\mathrm{Zn}$ deficiency is not unusual [62]. On the other hand, the prevalence of $\mathrm{Zn}$ deficiency in western countries is unknown, and may be very low. Furthermore, there are no data on sensitivity and specificity of the various tests, and apparently the available tests are suboptimal $[63,64]$. Further research is necessary to find a reliable marker for Zn deficiency, and to collect data on the importance of $\mathrm{Zn}$ status for growth in western societies. 
A further possible screening parameter could be a sweat test in an infant with a low length or weight for age. We investigated this in detail and concluded that such screening is not indicated, as the prior probability of $\mathrm{CF}$ is less than $1 \%$, and length or height are insensitive predictors [18]. If clinical symptoms or signs suggestive of CF are found in combination with growth faltering, further diagnostic steps are warranted, as the prior probability is then expected to be higher.

Based on the above considerations, we believe that, at present, laboratory screening of short children should include the parameters shown in table 5 .

\section{Conclusion}

Although growth monitoring has been performed for more than 100 years, until recently a scientific approach to assessing its efficacy and efficiency has been lacking. The guideline we proposed in 2008 may serve as a starting point for further validation studies and cost-benefit analyses. With respect to laboratory investigations, the scientific evidence base is also narrow, so that the major part is only based on theoretical considerations and clinical experience. Further studies are needed to assess how often short stature is the only clinical feature of the disorders which are candidates for laboratory testing.

\section{References}

1 Grote FK, Oostdijk W, De Muinck KeizerSchrama SM, Dekker FW, Verkerk PH, Wit JM: Growth monitoring and diagnostic work-up of short stature: an international inventorization. J Pediatr Endocrinol Metab 2005;18:1031-1038.

$\checkmark 2$ Wit JM, Clayton PE, Rogol AD, Savage MO, Saenger PH, Cohen P: Idiopathic short stature: definition, epidemiology, and diagnostic evaluation. Growth Horm IGF Res 2008, 18:89-110.

$\checkmark 3$ Cohen P, Rogol AD, Deal CL, Saenger P, Reiter EO, Ross JL, Chernausek SD, Savage MO, Wit JM: Consensus statement on the diagnosis and treatment of children with idiopathic short stature: a summary of the Growth Hormone Research Society, the Lawson Wilkins Pediatric Endocrine Society, and the European Society for Paediatric Endocrinology Workshop. J Clin Endocrinol Metab 2008;93:4210-4217.

$\checkmark 4$ Hermanussen M, Cole J: The calculation of target height reconsidered. Horm Res 2003; 59:180-183.

$\checkmark 5$ Sorva R: Growth evaluation: parent and child specific height standards. Arch Dis Child 1989;64:1483-1487.

$\checkmark 6$ Sorva R: Variation of growth in length and weight of children. I. Years 1 and 2. Acta Paediatr Scand 1990;79:490-497.

$>7$ Sorva R: Variation of growth in height and weight of children. II. After infancy. Acta Paediatr Scand 1990;79:498-506.

$>8$ Hall DM: Growth monitoring. Arch Dis Child 2000;82:10-15.

$\checkmark$ De Muinck Keizer-Schrama SMPF: Consensus 'diagnosis of short stature in children'. National Organization for Quality Assurance in Hospitals (in Dutch). Ned Tijdschr Geneeskd 1998;142:2519-2525.
$>10$ Fayter D, Nixon J, Hartley S, Rithalia A, Butler G, Rudolf M, Glasziou P, Bland M, Stirk L, Westwood M: Effectiveness and cost-effectiveness of height-screening programmes during the primary school years: a systematic review. Arch Dis Child 2008;93:278284.

11 Fry T: If it's worth doing, let's do it! Arch Dis Child 2008;93:267-268.

12 Hall D, Cole T, Elliman D, Gibson P, Logan S, Wales J: Growth monitoring. Arch Dis Child 2008;93:717-718.

13 Grote FK, Oostdijk W, De Muinck KeizerSchrama SMPF, van Dommelen P, van Buuren S, Dekker FW, Ketel AG, Moll HA, Wit JM: The diagnostic work up of growth failure in secondary health care; an evaluation of consensus guidelines. BMC Pediatr 2008;8: 21-29.

14 Van Buuren S, Bonnemaijer-Kerckhoffs DJA, Grote FK, Wit JM, Verkerk PH: Many referrals under Dutch short stature guidelines. Arch Dis Child 2004;89:351-352.

15 Grote FK, van Dommelen P, Oostdijk W, de Muinck Keizer-Schrama SMPF, Verkerk PH, Wit JM, Van Buuren S: Developing evidencebased guidelines for referral for short stat ure. Arch Dis Child 2008;93:212-217.

16 Grote FK: Assessment of Short Stature in Children; thesis, Leiden University, 2007.

17 van Dommelen P, Grote F, Oostdijk W, Keizer-Schrama S, Boersma B, Damen G, Csizmadia C, Verkerk P, Wit J, van Buuren S: Screening rules for growth to detect celiac disease: a case-control simulation study. BMC Pediatr 2008;8:35.

18 van Dommelen P: Evidence-Based Referral Criteria in Growth Monitoring; thesis, Leiden University, 2008.

19 Wit JM, Ranke M, Kelnar CJH: ESPE Classification of Paediatric Endocrine Diagnoses. Horm Res 2007;68(suppl 2):1-120.
20 Wit JM, Reiter EO, Ross JL, Saenger PH, Savage $\mathrm{MO}$, Rogol AD, Cohen P: Idiopathic short stature: management and growth hormone treatment. Growth Horm IGF Res 2008;18:111-135.

21 Cakan N, Kamat D: Short stature in children: a practical approach for primary care providers. Clin Pediatr 2007;46:379-385

22 Simm PJ, Werther GA: Child and adolescent growth disorders. Aust Fam Physician 2005; 34:731-736.

23 Rappold G, Blum WF, Shavrikova EP, Crowe BJ, Roeth R, Quigley CA, Ross JL, Niesler B: Genotypes and phenotypes in children with short stature: clinical indicators of SHOX haploinsufficiency. J Med Genet 2007;44: 306-313

24 Herber SM, Milner RD: Sitting heights in Sheffield, 1985: have standards changed? Acta Paediatr Scand 1987;76:818-823.

25 Hertel NT, Scheike T, Juul A, Main KM, Holm K, Bach-Mortensen N, Skakkebaek NE, Muller JR: Body proportions of Danish children. Curves for sitting height ratio, subischial length and arm span (in Danish). Ugeskr Laeger 1995;157:6876-6881.

-26 Tanaka C, Murara M, Homma M, Kawahara T: Reference charts of body proportion for Japanese girls and boys. Ann Hum Biol 2004; 31:681-689.

-27 Fredriks AM, van Buuren S, van Heel WJ, Dijkman-Neerincx RH, Verloove-Vanhorick SP, Wit JM: Nationwide age references for sitting height, leg length, and sitting height/ height ratio, and their diagnostic value for disproportionate growth disorders. Arch Dis Child 2005;90:807-812.

28 Turan S, Bereket A, Omar A, Berber M, Ozen A, Bekiroglu N: Upper segment/lower segment ratio and armspan-height difference in healthy Turkish children. Acta Paediatr 2005;94:407-413. 
29 Gerver WJ, de Bruin R: Pediatric Morphometrics: a Reference Manual. Maastricht, University Press Maastricht, 2001.

30 Batch J: Genetic syndromes and dysmorphology; in Brook CGD, Clayton PE, Brown RS (eds): Clinical Pediatric Endocrinology. Oxford, Blackwell, 2005, pp 113-123.

31 Cowell CT: Differential diagnosis of short stature and poor growth velocity; in Wass JAH, Shalet SM (eds): Oxford Textbook of Endocrinology and Diabetes. Oxford, Oxford University Press, 2002, pp 983-1008.

32 Oostdijk W: Diagnostics in growth disorders; in Wit JM, de Muinck Keizer-Schrama SMPF, Delemarre-Van de Waal HA (eds): Growth Disorders. Maarssen, Elsevier/ Bunge, 1999, pp 64-73.

- 33 Kant SG, Grote F, de Ru MH, Oostdijk W, Zonderland HM, Breuning MH, Wit JM: Radiographic evaluation of children with growth disorders. Horm Res 2007;68:310 315.

34 Richter-Unruh A, Knauer-Fischer S, Kaspers S, Albrecht B, Gillessen-Kaesbach G, Hauffa BP: Short stature in children with an apparently normal male phenotype can be caused by $45, \mathrm{X} / 46, \mathrm{XY}$ mosaicism and is susceptible to growth hormone treatment. Eur J Pediatr 2004;163:251-256.

35 Walenkamp MJE, Wit JM: Genetic disorders in the growth hormone - insulin-like growth factor-I axis. Horm Res 2006;66:221-230.

36 Greulich WW, Pyle SI: Radiographic Atlas of Skeletal Development of Hand and Wrist, ed 2. Stanford, Stanford University Press, 1959.

37 Tanner JM, Whitehouse RH, Cameron N: Assessment of Skeletal Maturity and Prediction of Adult Height (TW2 Method), ed 2. London, Academic Press, 1975.

38 van Rijn JCW, Grote FK, Oostdijk W, Wit JM: Short stature and the probability of coeliac disease, in the absence of gastrointestinal symptoms. Arch Dis Child 2004;89:882883.

39 Abdulkarim AS, Murray JA: The diagnosis of coeliac disease. Aliment Pharmacol Ther 2003:17:987-995.

40 Karimi M, Karamifar HA: Short stature in beta-thalassemia minor subjects. Med Sci Monit 2004;10:CR603-CR605.
41 Nunlee-Bland G, Rana SR, Houston-Yu PE, Odonkor W: Growth hormone deficiency in patients with sickle cell disease and growth failure. J Pediatr Endocrinol Metab 2004;17: 601-606.

42 Raiola G, Galati MC, De Sanctis V, Caruso NM, Pintor C, De Simone M, Arcuri VM, Anastasi S: Growth and puberty in thalassemia major. J Pediatr Endocrinol Metab 2003; 16(suppl 2):259-266.

43 Thomas PW, Singhal A, Hemmings-Kelly M, Serjeant GR: Height and weight reference curves for homozygous sickle cell disease. Arch Dis Child 2000;82:204-208.

44 Stephensen CB: Burden of infection on growth failure. J Nutr 1999;129(2S Suppl): 534S-538S.

45 Sokol RJ, Stall C: Anthropometric evaluation of children with chronic liver disease. Am J Clin Nutr 1990;52:203-208.

-46 Friedman J, Lewy JE: Failure to thrive associated with renal disease. Pediatr Ann 1978;7: 767-773.

47 Rizzoni G, Broyer M, Guest G, Fine R, Holliday MA: Growth retardation in children with chronic renal disease: scope of the problem. Am J Kidney Dis 1986;7:256-261.

48 Fine RN: Growth retardation in children with chronic renal insufficiency. Nephron 1997;76:125-129.

49 Mahan JD, Warady BA: Assessment and treatment of short stature in pediatric patients with chronic kidney disease: a consensus statement. Pediatr Nephrol 2006;21: 917-930.

50 Grote FK, Oostdijk W, De Muinck KeizerSchrama SM, Dekker FW, van Dommelen P, van Buuren S, Lodder-van der Kooij AM, Verkerk PH, Wit JM: Referral patterns of children with poor growth in primary health care. BMC Public Health 2007;7:77-83.

51 Bajpai A, Bagga A, Hari P, Bardia A, Mantan $\mathrm{M}$ : Long-term outcome in children with primary distal renal tubular acidosis. Indian Pediatr 2005;42:321-328.

52 Caldas A, Broyer M, Dechaux M, Kleinknecht C: Primary distal tubular acidosis in childhood: clinical study and long-term follow-up of 28 patients. J Pediatr 1992;121:233-241.

53 Caruana RJ, Buckalew VM Jr: The syndrome of distal (type 1) renal tubular acidosis. Clinical and laboratory findings in 58 cases. Medicine (Baltimore) 1988;67:84-99.
54 McSherry E: Acidosis and growth in nonuremic renal disease. Kidney Int 1978;14: 349-354.

55 Santos F, Friedman BI, Chan JC: Management of chronic renal failure in children. Curr Probl Pediatr 1986;16:237-301.

56 Casado de Frías E, Ruibal JL, Reverte F, Bueno G: Evolution of height and bone age in primary congenital hypothyroidism. Clin Pediatr (Phila) 1993;32:426-432.

57 Stochholm K, Gravholt CH, Laursen T, Jorgensen JO, Laurberg P, Andersen M, Kristensen LO, Feldt-Rasmussen U, Christiansen JS, Frydenberg M, Green A: Incidence of GH deficiency - a nationwide study. Eur J Endocrinol 2006;155:61-71.

58 Thomas M, Massa G, Craen M, de Zegher F, Bourguignon JP, Heinrichs C, De Schepper J, Du Caju M, Thiry-Counson G, Maes M: Prevalence and demographic features of childhood growth hormone deficiency in Belgium during the period 1986-2001. Eur J Endocrinol 2004;151:67-72.

59 Cianfarani S, Liguori A, Boemi S, Maghnie M, Iughetti L, Wasniewska M, Street ME, Zucchini S, Aimaretti G, Germani D: Inaccuracy of insulin-like growth factor (IGF) binding protein (IGFBP)-3 assessment in the diagnosis of growth hormone $(\mathrm{GH})$ deficiency from childhood to young adulthood: association to low GH dependency of IGF-II and presence of circulating IGFBP-3 18-kilodalton fragment. J Clin Endocrinol Metab 2005;90:6028-6034.

60 Davenport ML, Punyasavatsut N, Stewart PW, Gunther DF, Savendahl L, Sybert VP: Growth failure in early life: an important manifestation of Turner syndrome. Horm Res 2002;57:157-164.

61 Moreno-Garcia M, Fernandez-Martinez FJ, Barreiro ME: Chromosomal anomalies in patients with short stature. Pediatr Int 2005. 47:546-549.

62 Kaji M, Nishi Y: Growth and minerals. Growth Genet Horm 2006;22:1-7.

63 King JC: Assessment of zinc status. J Nutr 1990;120(suppl 11):1474-1479.

64 Wood RJ: Assessment of marginal zinc status in humans. J Nutr 2000;130:1350S-1354S. 